\title{
An Electron Microscope Study on the Oocyte, Test Cells and Follicular Envelope of the Tunicate, Molgula manhattensis ${ }^{1}$
}

\author{
Richard G. KeSSEL ${ }^{2,3}$ and Norman E. KEMP \\ Marine Biological Laboratory, Woods Hole, Massachusetts, Department of Anatomy, Bowman \\ Gray School of Medicine of Wake Forest College, and Department of Zoology, University of \\ Michigan
}

Received June 26, 1961

\begin{abstract}
Both inner follicle cells and test cells in the tunicate ovary appear to engage in active synthesis and secretion during growth of the oocyte. Both cell types contain prominent Golgi systems, numerous vesicles and cisternae of endoplasmic reticulum, and typical mitochondria. Two types of special inclusions develop in the inner follicle cells. The first is a homogeneous inclusion of low density which persists until the end of oogenesis. The second is a heterogeneous inclusion containing dense spheres in a less dense matrix. The Golgi material may synthesize the dense bodies but the matrix, at least in part, is probably contributed by endoplasmic reticulum. The heterogeneous inclusions degenerate and large vacuoles appear in the inner follicle cell late in oogenesis. Alignment of vesicles along the plasma membrane of follicle cells and formation of caveolae from the surface of oocytes suggest that pinocytosis may contribute to the transport of nutrients from follicle cells to oocyte. A distinctive feature in test cells is the differentiation of the nucleus into inner-dense and outer-light zones. The outer zone contains dense spots which give it a porous appearance. Positive reaction with the periodic acid-Schiff technique and metachromasia with toluidine blue suggest that the outer nuclear zone of the test cells may contain polysaccharide. The test cells appear to degenerate late in the development of the oocyte. The outer layer of follicle cells remains thin throughout oogenesis and does not appear active in synthesis and secretion. Changes occurring in the cytoplasm of the oocyte during oogenesis are also discussed.
\end{abstract}

Electron microscope studies on animal ovaries have dealt chiefly with changes in the cytoplasm of the growing oocyte and with the morphological relationships between the oocyte and its follicle or nurse cells. Published accounts include work on

1 Supported by grants (RG-6942, B-2748) from the National Institutes of Health, Public Health Service, and a grant (G-8773) from the National Science Foundation.

2 A portion of this investigation was carried out during the tenure of a postdoctoral fellowship from the Division of General Medical Sciences, United States Public Health service.

3 Present address: Department of Zoology, University of Iowa, Iowa City, Iowa. 
molluses $(29,46)$, echinoderms $(2,3)$, insects $(20)$, arachnids $(34,35)$, fishes $(18)$, amphibians $(14,16,43)$, birds $(28)$, and mammals $(4,9,22,36,38,41,45)$. As a contribution to comparative oogenesis, the present studies were undertaken to characterize the ultrastructure of oocytes, test cells, and follicle cells in a representative urochordate, Molgula manhattensis.

\section{MATERIALS AND METHODS}

Specimens of the tunicate, $M$. manhattensis, were obtained from the Woods Hole, Massachusetts, region during the month of July, and maintained in large aquaria provided with running sea water. For cytochemical observations with the light microscope, ovaries were excised and placed in 10\% formalin, Bouin's or Carnoy's fixatives. Stains included hematoxylin and eosin, Mallory's, toluidine blue, periodic acid-Schiff, and Sudan black B. For electron microscopy, small pieces of the ovary were fixed for 1 hour in a cold, $1 \%$ solution of osmium tetroxide in filtered sea water, buffered with acetate-veronal to $\mathrm{pH} 7.8$. The tissue was rapidly dehydrated in a graded series of alcohols, and embedded in a mixture of $n$-butyl and methyl methacrylates. Thin sections were obtained with a Porter-Blum microtome set to section at $0.025 \mu$. Sections were supported on athene grids coated with $0.1 \%$ Formvar in distilled ethylene dichloride, and stabilized with carbon. Electron microscopy was performed with RCA EMU 3D and 3F microscopes.

\section{OBSERVATIONS}

Some controversy concerning the origin of the follicle and test cells in tunicate ovaries exists, but the general description that follows is based on the work of Seeliger (33) and Tucker (39). Other viewpoints concerning the origin of the follicle and test cells may be obtained by consulting Van Beneden and Julin (40), Spek (37), and Knaben (21).

It is generally believed that both ova and primary follicle cells arise from "indifferent" cells of the germinal epithelium. The ova then become surrounded by a single layer of cells, the primary follicle. Test cells differentiate from the primary follicular epithelium (or from inner follicle cells subsequent to their differentiation) and become compressed into the peripheral cytoplasm of the egg. The primary follicle then differentiates into an inner and outer follicular epithelium. The ova retain their connection with the ovary by means of follicle stalks continuous with the germinal epithelium and the outer follicle. At some point during the development of these cell layers, a chorion is secreted between test cells and follicle cells, and a basement membrane is formed on the outer side of the latter. These final relationships are shown diagrammatically in Fig. 1, which is intended to provide a guide for the following electron microscope descriptions. 


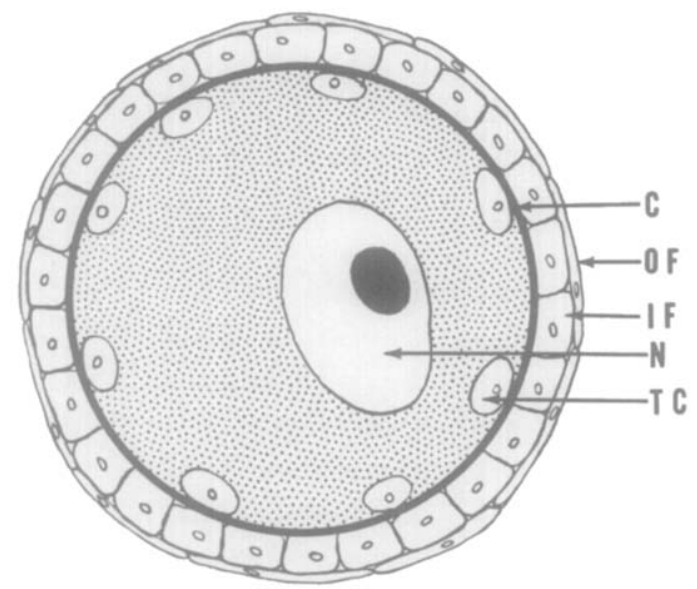

FIG. 1. Diagram to show relationship of inner follicle cell $(I F)$, outer follicle cell $(O F)$, test cell $(T C)$, and chorion $(C)$. Nucleus of oocyte $(N)$. Oocyte cytoplasm stippled.

\section{Follicular cells}

A low-power electron micrograph of a young oocyte is shown in Fig. 2. At this stage the oocyte is surrounded by two flattened layers of follicular cells. Numerous mitochondria and elements of the endoplasmic reticulum are scattered throughout the cytoplasm of the oocyte. A large nucleolus is present. Epithelial cells of the inner follicular layer contain relatively few mitochondria, and elements of the endoplasmic reticulum and Golgi material (Figs. 6 and 7) are just beginning to develop. Test cells migrate from the inner follicular layer and protrude into the outer surface of the oocyte (Figs. 6 and 7). A thin, homogeneous layer, the chorion or vitelline membrane, is then secreted between the inner follicular epithelium and egg cytoplasm (Figs. 6 and 7). Test cells thus become isolated from the follicular epithelium and subsequently become embedded in the egg cytoplasm (Figs. 6, 15 and 18).

The inner follicular layer proceeds to thicken and soon becomes cuboidal (Fig. 3). As the follicle cells grow, one of the most obvious changes is in the prominence of the endoplasmic reticulum. The endoplasmic reticulum, consisting of vesicles, lamellae, cisternae, and associated ribosomes, becomes greatly dilated (Figs. 8 and 9), and comes to occupy a considerable portion of the cytoplasm. The Golgi material in the inner follicle cells is in the form of a series of compact, smooth-membraned lamellae and vesicles of different sizes (Figs. 8, 9 and 10). Mitochondria are distributed throughout the cytoplasm (Figs. 8 and 9). The nucleus is surrounded by a double-layered membrane and contains a nucleolus.

Two types of inclusions are characteristic of the inner follicular cells: (1) spherical, 
homogeneous inclusions of medium electron density (Figs. 3, 13, 14, 15 and 17), and (2) a heterogeneous type consisting of one or more highly electron-dense spherical masses embedded within a less dense matrix (Figs. 11 and 12). How the latter type of inclusion develops is suggested by the micrographs. Small, heterogeneous inclusions form in association with vesicles of the Golgi material (Figs. 10 and 11). These small inclusions appear to be young stages in the development of a fully formed heterogeneous inclusion such as that illustrated in Figs. 11 and 12. It seems probable that the large inclusions are formed by fusion of smaller ones. Possible assembly of the large, heterogeneous inclusions occurs within the cisternae of the endoplasmic reticulum; for the matrix of the inclusions resembles the material sometimes seen in the cisternae (Figs. 12 and 18). In addition, the endoplasmic reticulum is often continuous with the periphery of a heterogeneous inclusion which appears fully formed (Fig. 12). As the inner follicle cells grow, they become filled with endoplasmic reticular vesicles (Figs. 11-13). Some are aligned along the plasma membrane of the cell adjacent to the chorion, and may even be in contact with the plasma membrane. This structural relationship suggests a mechanism for the release of material from inner follicle cells through fusion of vesicles with the plasma membrane and extrusion of their contents into the substance of the chorion. Microvilli projecting from the inner follicle cells into the matrix of the chorion (Fig. 16) provide a very large surface area for these cells.

With further growth, yolk platelets are deposited in the oocyte (Fig. 4). As yolk deposition nears completion, large vacuoles (Figs. 5 and 13-15) appear in cells of the inner follicular layer. Most of the small vesicles have by this time disappeared from the periphery next to the chorion. A characteristic feature of this stage is the degenerated appearance of the heterogeneous inclusions within a large vacuolar space. The progressive dissolution of the heterogeneous inclusion seems to correspond to the increasing size of the vacuole (Figs. 13-15). On the other hand, the homogeneous inclusions formed during growth of the follicle cells show no signs of degeneration during late oogenesis (Figs. 13-15).

Throughout oogenesis the outer follicular envelope remains extremely thin (Figs. 2, 3 and 6). Its cells contain small numbers of mitochondria and elements of the endoplasmic reticulum. However, the cells never appear to be engaged actively in secretory

FIG. 2. Young oocyte with flattened follicular envelope $(F E) . \times 2100$.

FIG. 3. Later stage after the inner follicle cells $(I F)$ have become cuboidal. Chorion present. Outer follicle cell $(O F)$. Portion of a younger oocyte with only a single cell layer constituting the follicular envelope $(F E)$ shown above. $\times 2700$.

FIG. 4. Still later stage in oocyte development after yolk deposition in oocyte cytoplasm $(O)$. Test cell $(T C) . \times 2000$.

FIG. 5. Portion of cytoplasm of oocyte $(O)$ late in development. Inner follicle cells $(I F)$ have enlarged, vacuoles are beginning to appear, and inclusion material is present in some of the vacuoles. $\times 4300$. 

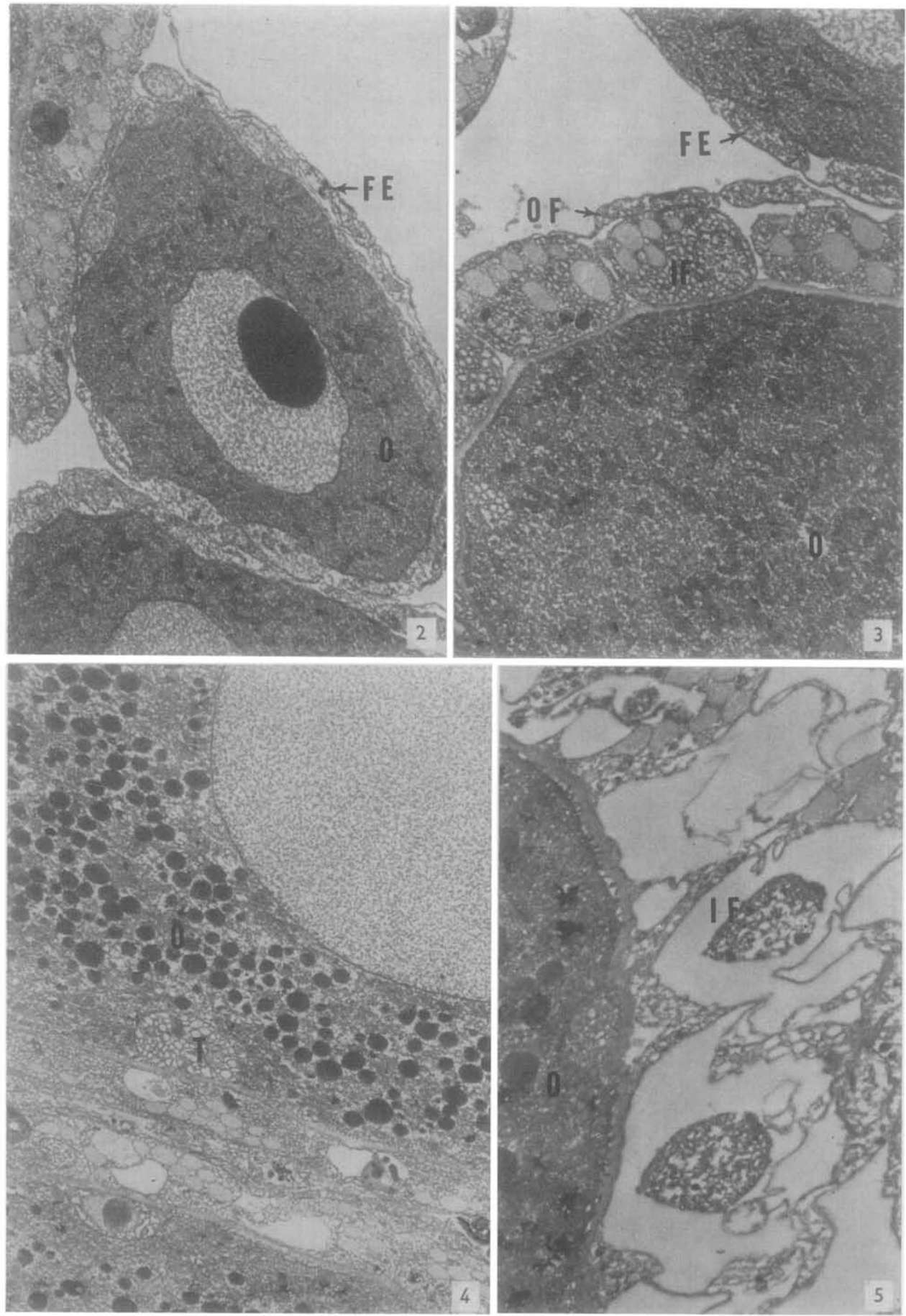

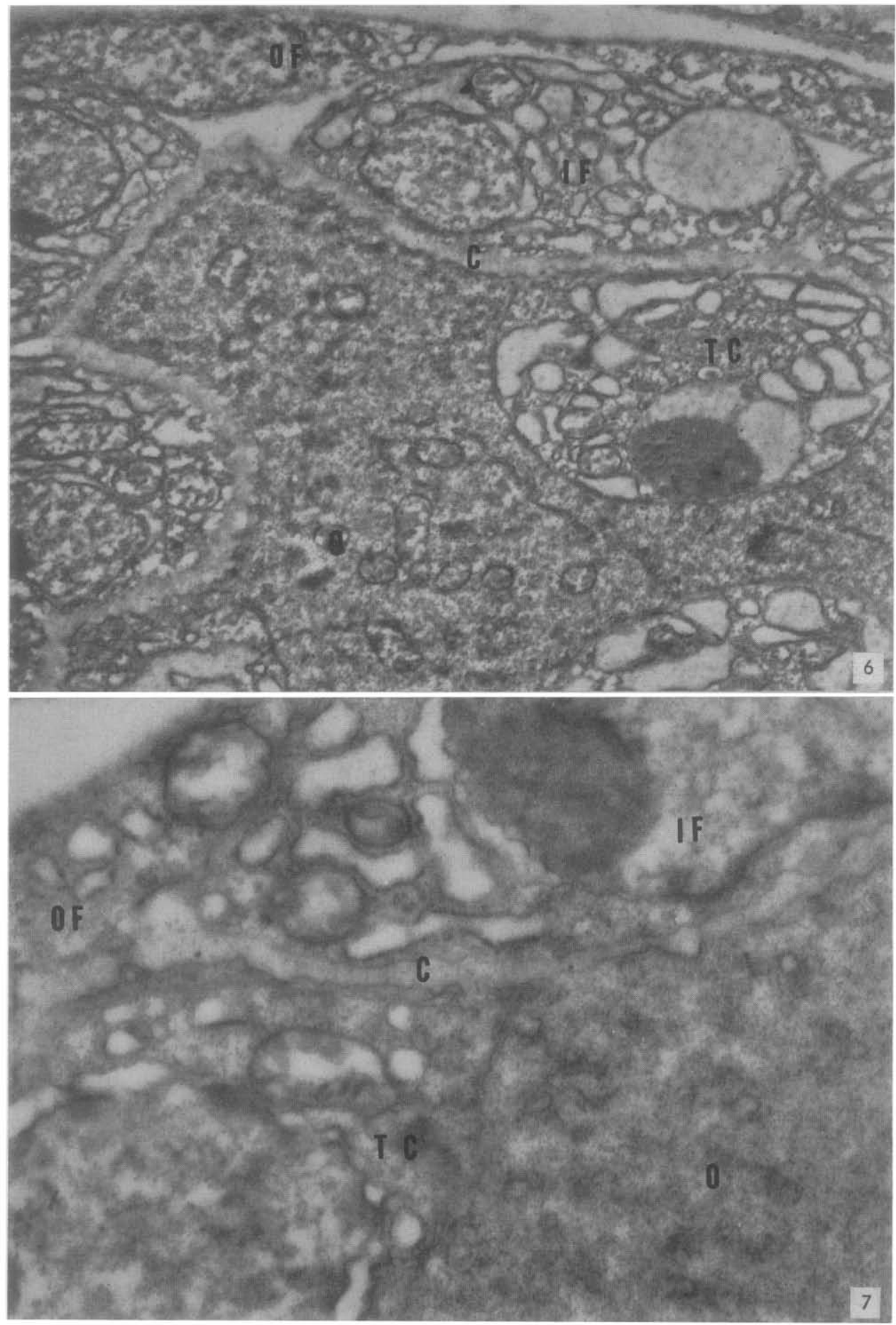


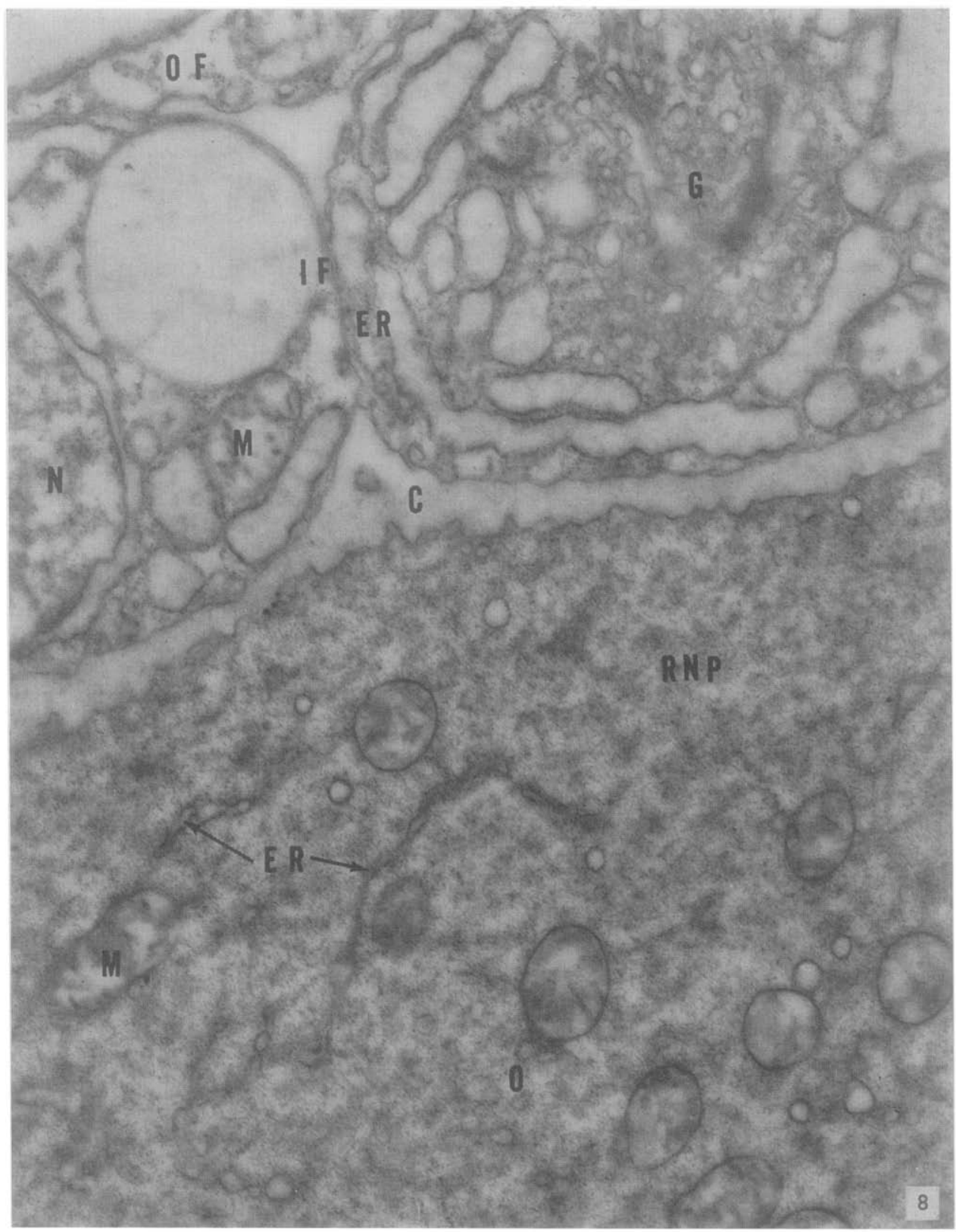

FIGs. 6-7. Young stages in the oocyte development showing outer follicle cells $(O F)$, inner follicle cells $(I F)$, test cells $(T C)$, chorion $(C)$, and oocyte cytoplasm $(O)$. Consult text for further discussion. Fig. 6, $\times 8200$; Fig. 7, $\times 26,200$.

FIG. 8. Micrograph showing portions of the cytoplasm of a young oocyte $(O)$, inner follicle cells $(I F)$, outer follicle cell $(O F)$, and chorion $(C)$. Mitochondria $(M)$, Golgi material $(G)$, endoplasmic reticulum $(E R)$, ribosomes $(R N P)$, and nucleus of inner follicle cell $(N)$ are identified. $\times 20,400$. 
activity. A thin basement membrane is present along the outer margin of inner follicular cells (Fig. 17), and there are fine filaments in the intercellular space between follicular cell layers.

It has been shown (39) that a connection exists between the follicle cells of each oocyte and the germinal epithelium of the ovary. This structure, known as a follicle stalk, appears as a strand or narrow sheet of cells surrounding a lumen. Small, branched microvilli project from the apical surface of these cells into the lumen. The external germinal epithelium of the ovary consists of ciliated, columnar cells, but the cells become flattened as one approaches the portion invaginated into the ovarian cavity.

The structure of the cilium in germinal epithelial cells is typical of that described in other forms, i.e., it contains nine peripheral fibrils and two central ones. The cilium terminates in a basal corpuscle similar to that described in the mollusc Elliptio (13). From the basal portion of the corpuscle extend banded "rootlets" with an axial periodicity of $600-700 \AA$. Further details will be published elsewhere.

\section{Test cells}

For some time after the test cells have migrated into the cytoplasm of the oocyte, they resemble the follicular epithelial cells in their pattern of differentiation (Figs. 6 and 7). Golgi material becomes prominent in the test cells (Figs. 19 and 20) just as in follicular epithelium (Figs. 8 and 9). This material consists of long, parallel, smooth-surfaced membranes and associated vesicles. Rough-surfaced elements of endoplasmic reticulum are also well-developed in test cells and occupy much of the cytoplasm extending from the nucleus to the plasma membrane (Figs. 18 and 20). Dilation of cisternae probably coincides with pronounced secretory activity. Mitochondria are often compressed between membranes of the endoplasmic reticulum (Fig. 18). Cytoplasm of test cells is completely separated from oocyte cytoplasm by plasma membranes of the two types of cells enclosing a thin interspace (Fig. 20). As the nucleus of the test cell differentiates, its contents become separated into two zones, an inner dense mass and a peripheral, less dense region (Figs. 18 and 20). A regular pattern of dense spots within the light zone (Figs. 18 and 20) gives this region a porous appearance, although it is by no means certain that the spots actually

FIG. 9. Portion of oocyte $(O)$, chorion $(C)$, and inner follicle cell containing endoplasmic reticulum $(E R)$, Golgi material $(G)$, vacuoles $(V)$. Nucleus $(N) . \times 26,000$.

FxG. 10. Portion of inner follicle cell with Golgi material $(G)$. Note small, electron-dense, spherical structures within vesicles of the Golgi material (arrows). Chorion $(C) . \times 26,000$.

FIG. 11. Inner follicle cell showing nearly completed hetereogeneous inclusion $(H I)$. Elements of Golgi material $(G)$ also visible. Note small, dense bodies within vesicles of Golgi (arrows). Chorion (C). $\times 20,200$. 


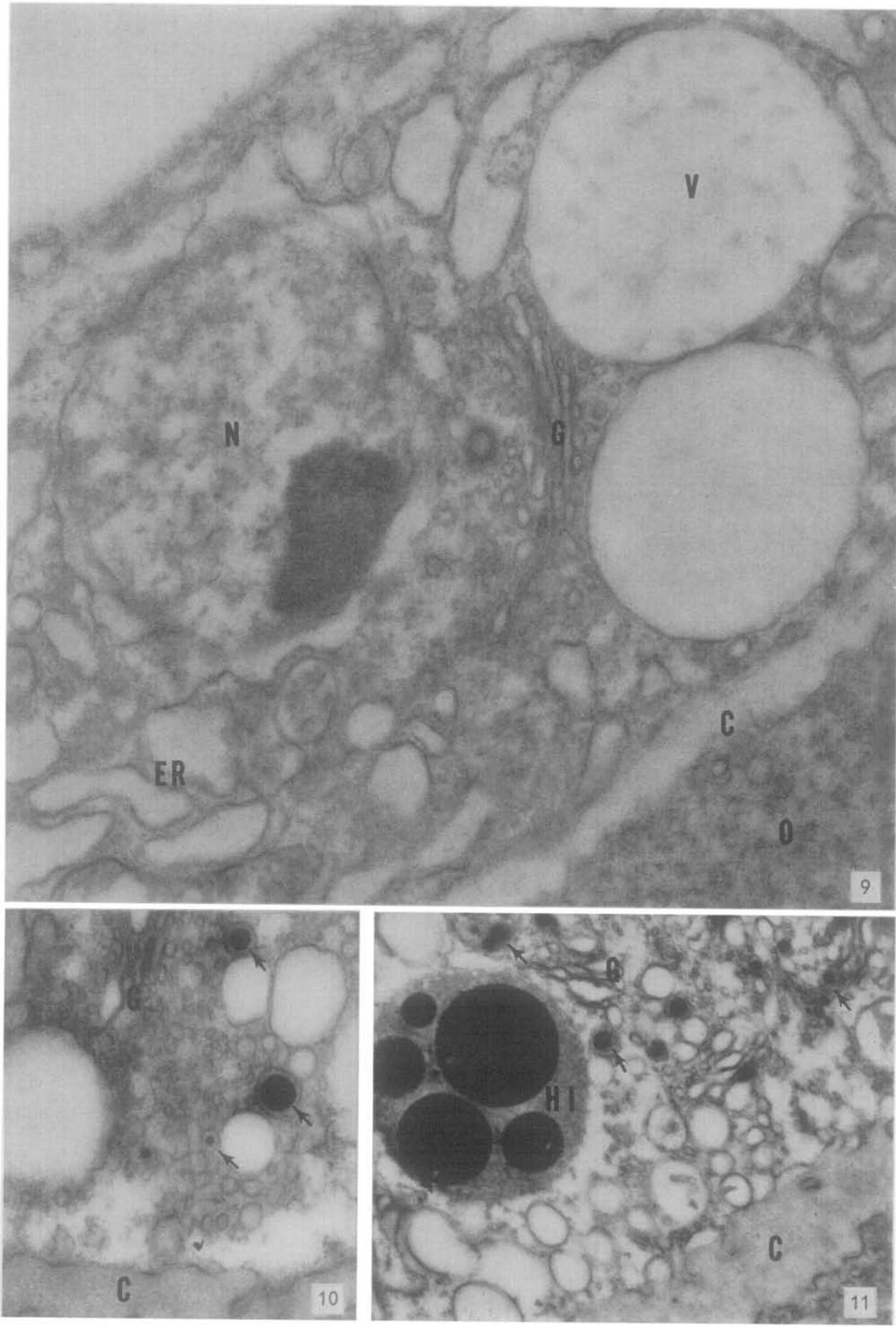

5-62173313 J. Ultrastructure Research 

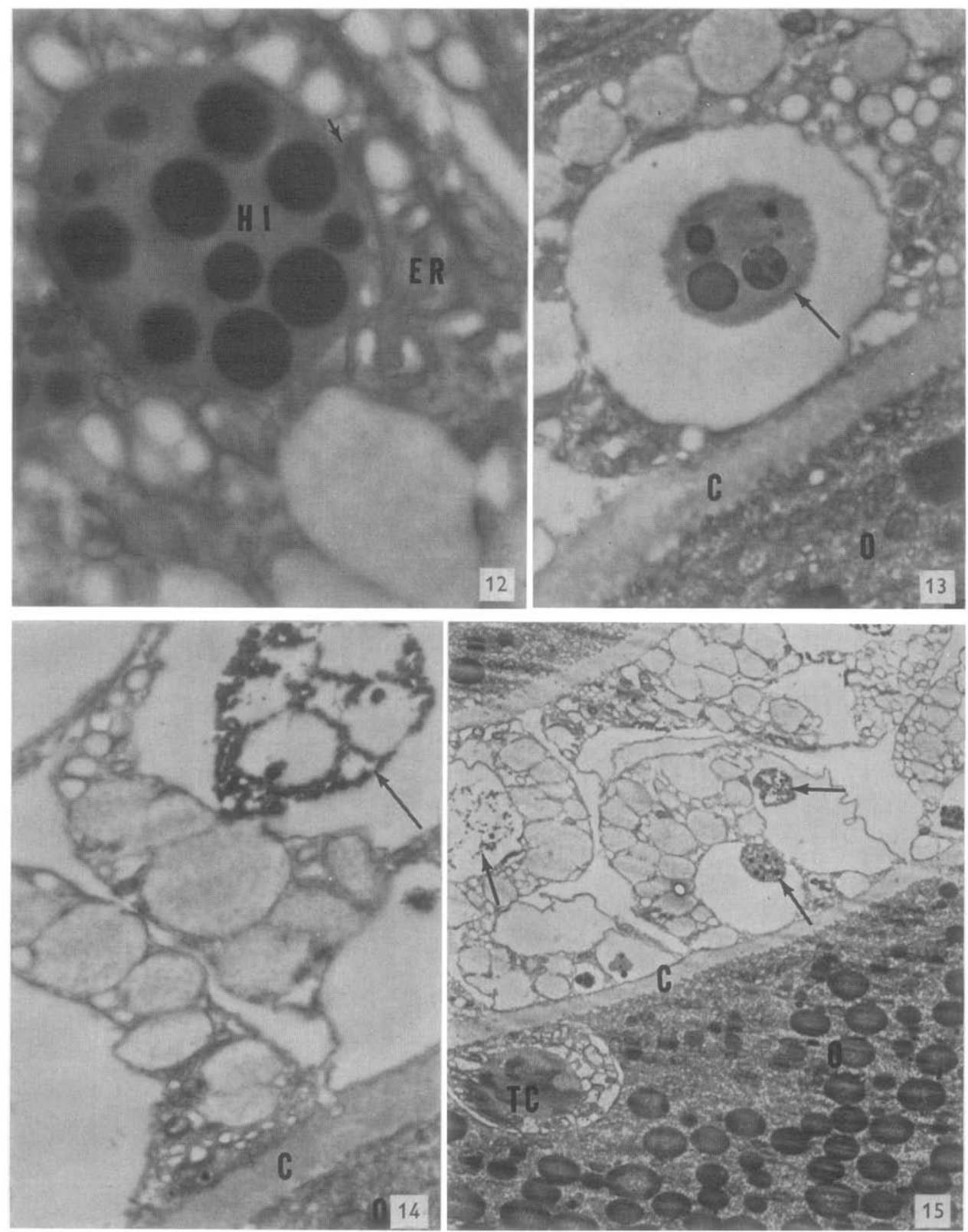

FIG. 12. Inner follicle cell containing a heterogeneous inclusion $(H I)$, and endoplasmic reticulum $(E R)$ containing material of similar density to the matrix of the inclusion. Apparent continuity of $E R$ with inclusion at arrow. $\times 13,000$.

FIGS. 13-15. Stages selected to show the progressive granulation or dissolution of the heterogeneous inclusion body (arrows) within vacuoles in the inner follicle cells. Homogeneous inclusions are also observed in inner follicle cells. Oocyte $(O)$, test cell $(T C)$, chorion $(C)$. Fig. 13, $\times 6500$; Fig. 14, $\times 6500$; Fig. 15, $\times 2900$.

FrG. 16. Portion of inner follicle cell $(I F)$ and oocyte $(O)$ showing microvillous projections into the chorion $(C)$. Invaginations of the oocyte plasma membrane and caveolae formation are indicated at arrows. $\times 14,000$.

FIG. 17. Portion of outer follicle cell $(O F)$ and inner follicle cell $(I F)$. Note homogeneous inclusion $(I)$ of moderate electron density. Basement membrane material and fine filaments located between inner and outer follicle cells. $\times 9400$.

FIG. 18. Portion of inner follicle cell $(I F)$, test cell $(T C)$, and oocyte $(O)$. Chorion $(C) . \times 11,700$.

FIG. 19. Test cell showing nucleus $(N)$, Golgi material $(G)$, mitochondria $(M)$, and vesicles of endoplasmic reticulum. $\times 28,800$. 


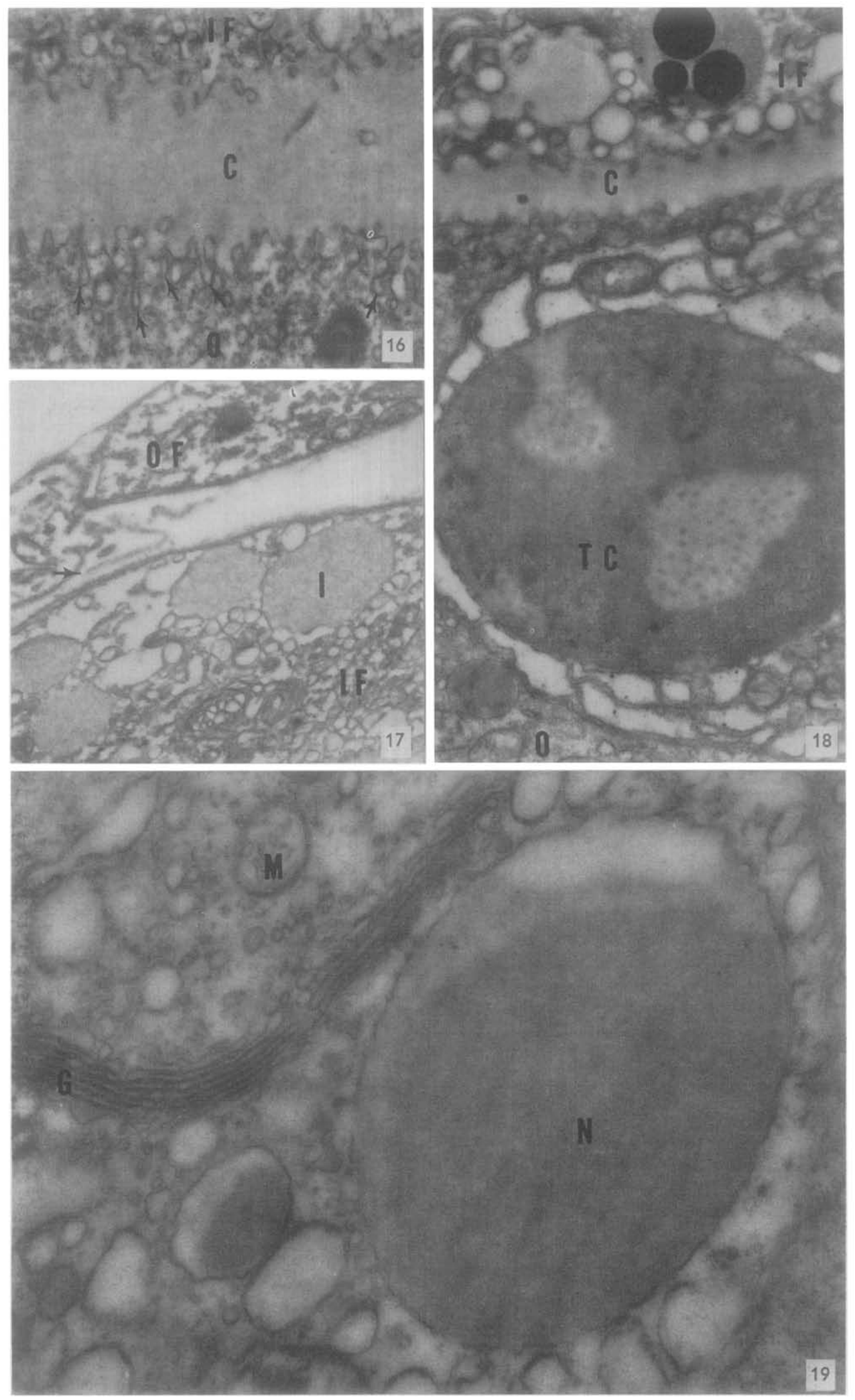


correspond to the pores in the nuclear membrane, as described in a variety of cell types $(1,5,8,14,42)$. The nucleus may be constricted, and it occupies a considerable portion of the total cytoplasm of the test cell (Fig. 20). The outer layer of the nuclear membrane is continuous with elements of the endoplasmic reticulum (Fig. 18 and 20). Some of the test cells appear to degenerate in older oocytes (Fig. 22).

Periodic acid-Schiff reactive inclusions are present both in the inner follicle cells and test cells very soon after their formation (Fig. 25). The PAS-reactivity of the test cells appears to be due to the material in the osmiophobic outer zone of the nucleus. Staining with toluidine blue also demonstrates a metachromatic mass in the test cells (Fig. 24). Because of the fact that each test cell has a single metachromatic mass similar in size to the nucleus, it is suggested that the osmiophobic zone of the nucleus is also responsible for the distribution of metachromasia.

\section{Oocyte}

Prior to the appearance of yolk, the egg cytoplasm is abundantly supplied with lamellae of endoplasmic reticulum, mitochondria, Golgi material, and groups of small particles approximately $100-200 \AA$ in diameter, probably representing RNP particles (24) (Figs. 6, 7, 8 and 9). While the small particulates may occur singly, they are also associated with vesicles and cisternae of the endoplasmic reticulum (Fig. 8). Another component of the oocyte cytoplasm is one which has been described in other forms as the multivesicular body $(4,36)$. This structure is a spherical unit, approximately $0.6 \mu$ in diameter, bounded externally by a membrane. Internally, it is composed of numerous vesicles approximately $35-50 \mathrm{~m} \mu$ in diameter (Fig. 21). The multivesicular bodies in the young oocyte are randomly distributed, and occur in relatively small numbers, but eventually become more numerous in the peripheral portions of the oocyte. It seems likely that they correspond to the cortical granules of echinoderm or vertebrate oocytes. The multivesicular bodies are readily distinguishable from mitochondria in low-power micrographs by their greater density, and at higher magnification by their internal structure.

The oocyte plasma membrane adjacent to the chorion is thrown into microvillous projections extending into the matrix of the chorion (Fig. 16), as is also true for the inner follicle cells. Small vesicles are numerous along the plasma membrane of the oocyte, and some appear continuous with the latter. Minute invaginations of the plasma membrane (caveolae intracellularis of Yamada (44)) are abundant (Fig. 16), suggesting that the growing oocyte nourishes itself in part through pinocytosis.

Oocyte nucleoli are readily recognizable in material prepared for electron microscopy. Sections taken through oocytes show the nucleolus as a ring-shaped structure consisting of a thick, extremely electron-dense wall surrounding a less dense center. 


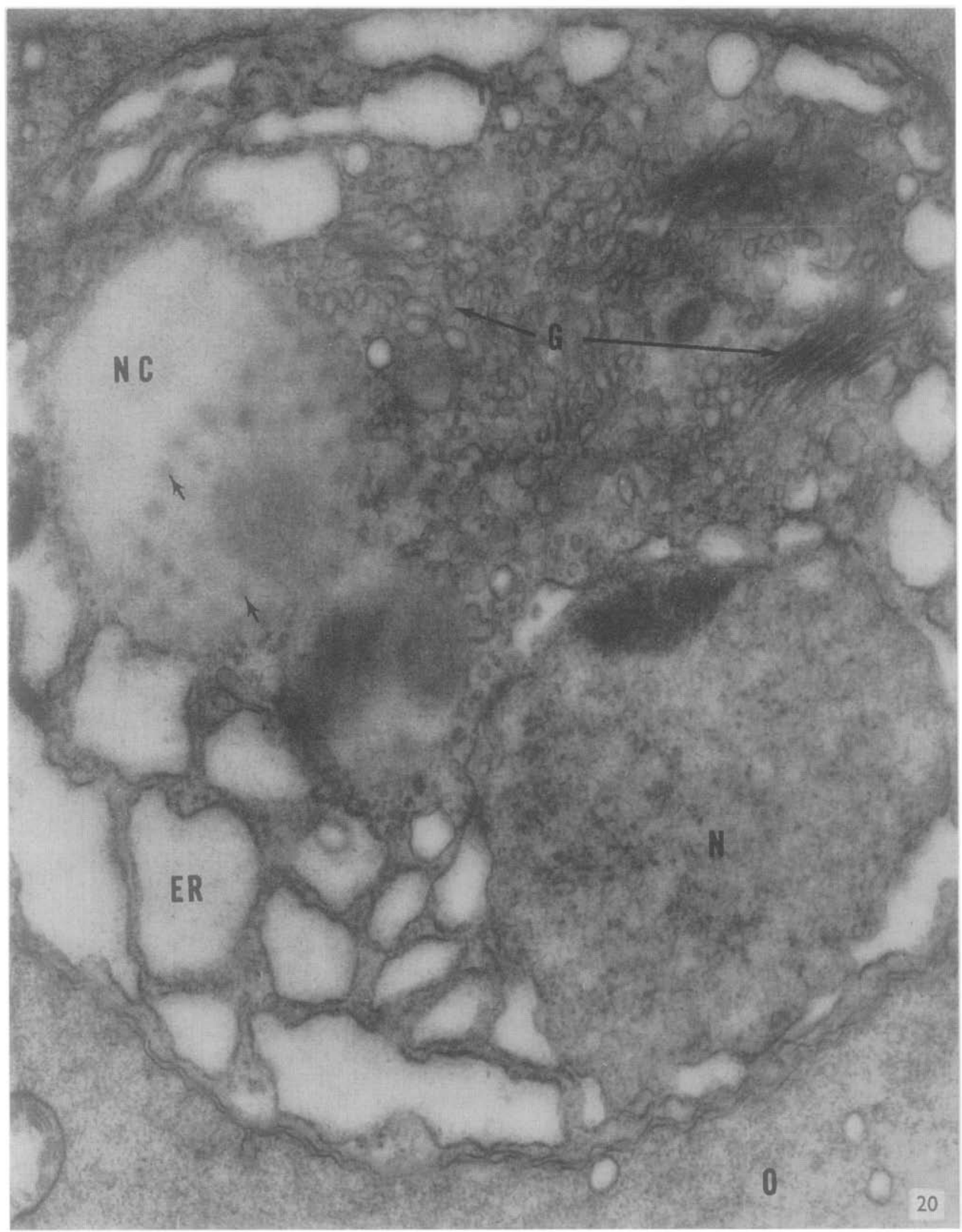

FrG. 20. Test cell showing prominent endoplasmic reticulum $(E R)$ and Golgi material $(G)$. Nucleus $(N)$ and outer, osmiophobic covering of nucleus $(N C)$, containing regions giving appearance of pores (arrows). Oocyte $(O)$. $\times 26,000$. 
The size of the nucleolus increases as the oocyte grows. Nucleoli having diameters of approximately $14 \mu$ were observed.

Yolk platelets accumulate throughout the cytoplasm of advanced oocytes (Figs. 4 and 22). The light center and dense periphery (Fig. 22) of platelets seem to be characteristic, but detailed fine structure has not been worked out. The peripheral portion of the platelets appears to consist of fine granules or rods packed into a crystalline array, while the substance of the central region appears to be packed more loosely.

The staining reaction of the cytoplasm of the oocytes varies from an intense basophilia in the young oocyte (Fig. 23), to an intense acidophilia in the larger oocytes containing yolk platelets. The PAS-staining reaction of the cytoplasm of young oocytes is not intense (Fig. 25), while the reaction in larger oocytes is intensely positive. The chorion is also PAS-reactive.

\section{DISCUSSION}

The morphological relationships of follicular epithelial cells and oocytes in the tunicates are essentially similar to those described for various vertebrate groups $(4,9,14,18,22,36,38,41,45)$. That is, the developing oocyte is surrounded by a follicular envelope separated from the oocyte by a thin vitelline membrane, commonly called the chorion. In addition, small projections of oocyte and follicle cell cytoplasm project into the matrix of the chorion. The electron microscopic observations made in the present investigation have not provided any evidence of a direct communication or continuity between oocyte and follicle cells in tunicates. The short, microvillous processes of oocyte and follicle cells were never observed to project completely through the matrix of the chorion (vitelline membrane). In other forms, some authors have considered the follicle cell prolongations as anastomotic bridges connecting the cytoplasm of follicle cell and oocyte $(26,31)$; others consider them to be extensions of the follicle cells that end at the oocyte surface, resulting in a contact relationship only $(7,10,30)$. Recently Duryee (11), from microdissection studies of living human ovarian ova, proposed again the existence of a direct communication (continuity) between the oocyte cytoplasm and that of the corona cells. The concept of protoplasmic bridges between oocyte and follicle cells (17) has proven untenable for vertebrates, which have been adequately studied with the electron microscope,

FIG. 21. Peripheral portion of oocyte cytoplasm showing chorion $(C)$, vesicular elements of endoplasmic reticulum $(E R)$, mitochondria $(M)$, and several membrane-limited, dense vesicular bodies $(V B) . \times 25,400$.

FIG. 22. Oocyte $(O)$ late in development after yolk formation $(Y)$ complete. Chorion $(C)$. Note degenerating appearance of test cell $(T C)$, and absence of plasma membranes separating the test cell and oocyte. $\times 20,400$. 

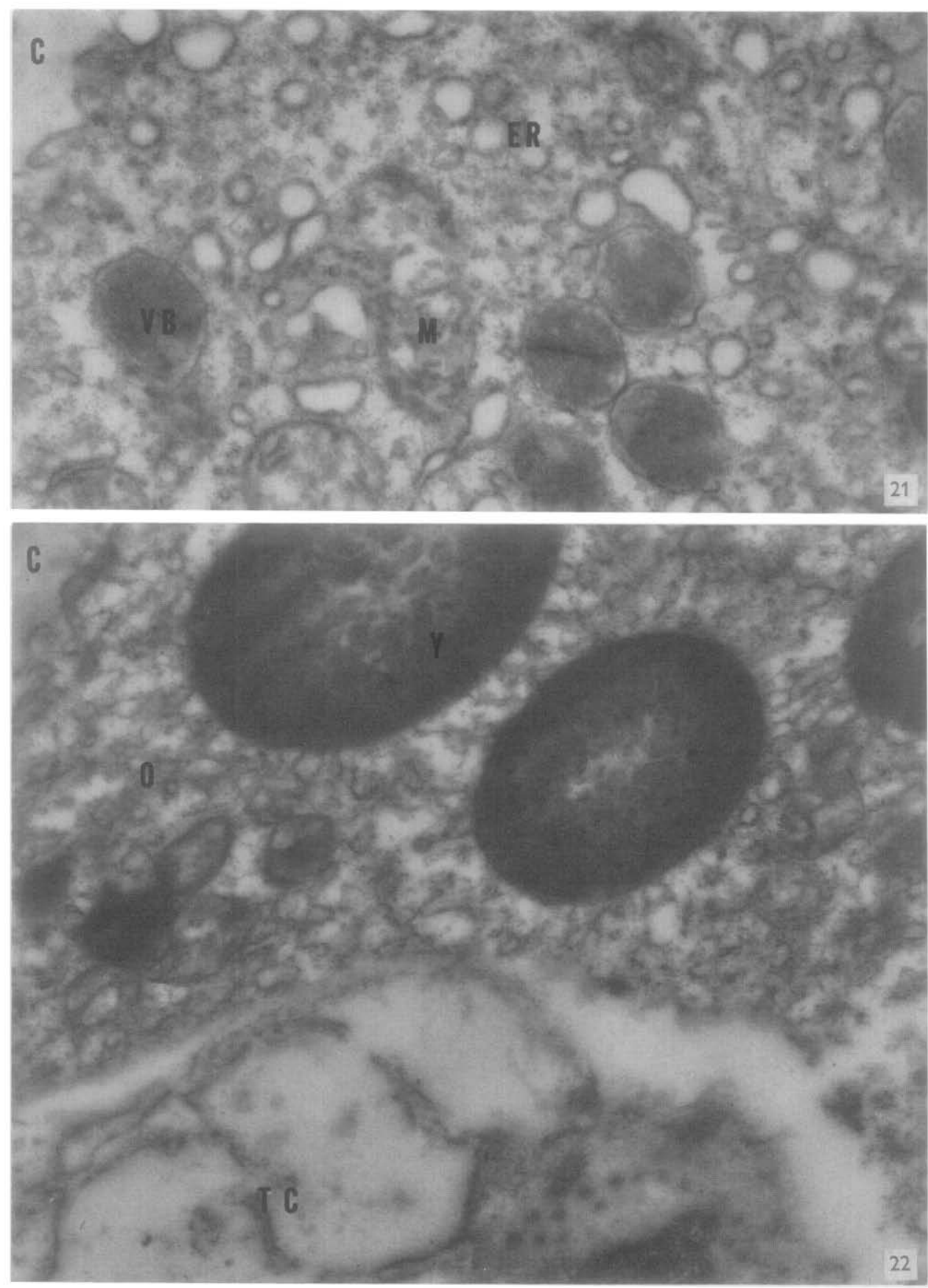
although contacts between the oocyte and processes from follicular epithelial cells may be maintained during oogenesis in some species $(4,36,38)$. The microvilli from the oocyte undoubtedly increase the absorptive area, as Kemp (16) has already pointed out. It should be noted that they are prominent during the development of the oocytes when materials for growth are required, a correlation noted also in vertebrates $(4,36,38)$.

The cytoplasmic morphology observed both in the follicular epithelial cells and in the oocyte suggests a possible mechanism for transport of nutriment through the vitelline membrane. This mechanism may involve a process of microvesiculation of the plasma membrane known as micropinocytosis, a mechanism of transport described in a variety of cells in both vertebrates and invertebrates $(6,19,23,25)$. In a recent paper by Press (28) on the fine structure of an avian egg, the author suggested that the egg receives nourishment by engulfing "... portions of follicle cells in a manner resembling pinocytosis." No evidence indicating that portions of the extensions of inner follicle cells are engulfed was found in the tunicate. It appears that the follicle cells synthesize nutritive material which is temporarily stored and then released into the matrix of the chorion. Nutriment then may enter the oocyte cytoplasm by a vesiculation of its plasma membrane. A similar sequence of events involving transport of raw materials across the zona pellucida of mammalian eggs has been suggested by Trujillo-Cenoz and Sotelo (38) and Anderson and Beams (4).

Of particular interest in tunicates are the test cells, which have no counterpart in the vertebrates thus far examined. The test cells appear to be involved in active synthesis and secretion throughout the period of growth of the oocyte, for they develop vacuoles similar to those which develop in the inner follicle cells. Test cells maintain their individuality within the oocyte throughout its most active growing period, but may degenerate toward the end of oogenesis. Probably the test cells function somewhat like the follicular epithelium in helping to nourish the growing oocyte; but we have no real understanding of their metabolism. Subsequent to ovulation and fertilization, what remains of the degenerated test cells may become incorporated into the oocyte cytoplasm. Although shortly after their formation the test cell and inner follicle cell nuclei appear morphologically similar, the test cell nucleus develops differently. The material of low electron density constituting the peripheral zone of test cell nuclei is PAS-reactive and reacts metachromatically with toluidine blue,

FIG. 23. Photomicrograph of young oocyte and portion of follicular envelope. $H$ and $E$. $\times 1800$. FIG. 24. Photomicrograph of oocyte stained with toluidine blue, showing metachromatic mass in test cells $(T C) . \times 1000$.

FIG. 25. Photomicrograph of oocyte stained with periodic acid-Schiff, showing PAS reactivity in test cells $(T C)$, chorion, and in cytoplasm of larger oocytes. $\times 1000$. 

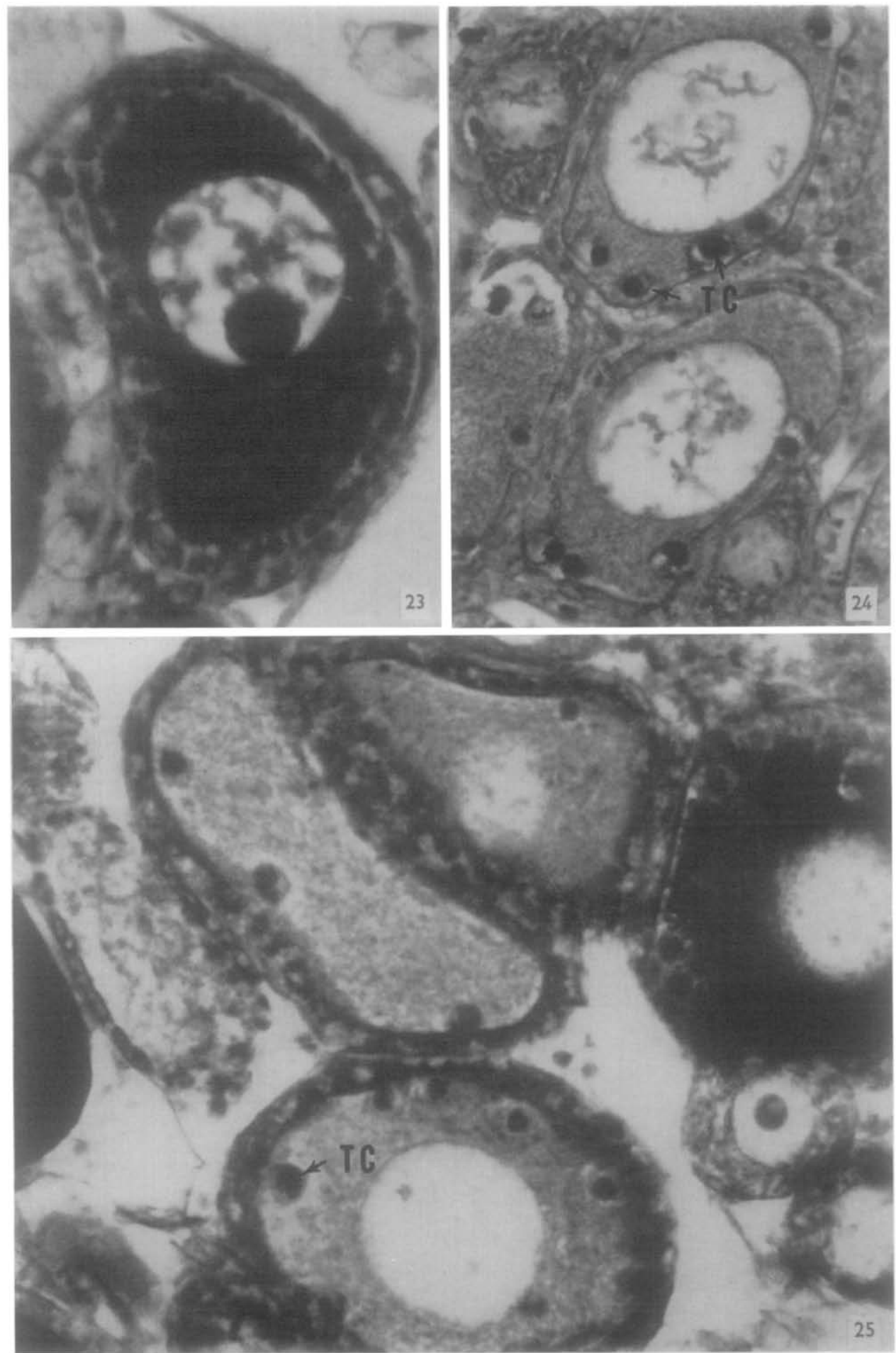
suggesting that it may contain polysaccharide. The significance of this differentiation is not known.

The multivesicular bodies described here for cytoplasm of the tunicate oocyte are similar to those reported in the oocytes of other species $(4,34,36)$. Such bodies may also appear in other cell types. In the rat ovum, they are described as spherical membrane-limited structures varying from 0.1 to $0.6 \mu$ in diameter, containing numerous small vesicles, $10-50 \mathrm{~m} \mu$ in diameter, and a denser central region of more closely packed vesicles, which is referred to as the nucleoid (36). The multivesicular body has been reported, often without the presence of the nucleoid, in neurons (27), regenerating nerve fibers (12), in intestinal epithelial cells (47), basophiles (24), ciliary epithelium (15), and Chlamydomonas (32). Sotelo and Porter (36) have suggested that the multivesicular body is a constant component in animal cells. Its functional significance remains obscure.

Of considerable interest is the possible mechanism by which the large, heterogeneous inclusion bodies arise in the inner follicle cells. The fully formed inclusion at its largest size is $2-3 \mu$ in diameter, and consists of spherical, highly electron-dense bodies embedded in a less dense matrix; the entire structure is limited by a membrane. Electron-dense bodies vary in diameter from those just visible to those approximately $1 \mu$ across. As many as 20 such bodies have been observed within a single inclusion. As was pointed out, the small, electron-dense bodies appear to have their origin within the vesicles of the Golgi complex. Based on similarities in appearance, the matrix component of the inclusion appears to be associated in its origin with the endoplasmic reticulum. In addition, instances are observed in which matrix of the inclusion body may be connected with matrix-filled membranous lamellae of the endoplasmic reticulum. The morphological observations that the matrix of the inclusion body arises in association with the endoplasmic reticulum provides a clue that it may be protein. Furthermore, the origin of the dense spherules in the Golgi complex indicates that they may be principally lipoidal. The functional significance of the heterogeneous inclusions, which develop only in the inner follicle cells, is not understood. Neither is the significance of the homogeneous inclusions in cells of this layer. However, there may be some correlation between the apparent breakdown or dissolution of the heterogeneous inclusion, and the appearance of large vacuoles in the inner follicle cells which occur late in development of the oocyte-follicle cell complex. 


\section{REFERENCES}

1. Afzelius, B. A., Exptl. Cell Research 8, 147 (1955).

2. - ibid. 11, 67 (1956).

3. Z. Zellforsch. u. mikroskop. Anat. 45, 660 (1957).

4. ANDERson, E. and BeAms, H. W., J. Ultrastructure Research 3, 432 (1960).

5. Beams, H. W., Tahmisian, T. N., Anderson, E. and Wright, B., J. Ultrastructure Research 5, 166 (1961).

6. Bennett, H. S., J. Biophys. Biochem. Cytol. 2, 99, Suppl. (1956).

7. CAJAL, P. R., Trabajos lab. invest. biol. Univ. Madrid 16, 279 (1918).

8. Callan, H. G. and Tomlin, S. G., Proc. Roy. Soc. London B 137, 367 (1960).

9. Chiquolne, A. D., Anat. Record 133, 258 (1959).

10. del Rio Hortega, P., Trabajos lab. invesi. biol. Univ. Madrid 11, 163 (1913).

11. Duryee, W. R., Trans. N. Y. Acad. Sci. Ser. 2, 12, 103 (1954).

12. Estable, C., Acosta Ferretra, W. S. and Sotelo, J. R., Z. Zellforsch. u. mikroskop Anat. 46, 387 (1957).

13. Fawcett, D. W., in S. L. Palay (Ed.), Frontiers in Cytology. Yale University Press, New Haven, 1958.

14. Gall, G., J. Biophys. Biochem. Cytol. 2, 393 Suppl. (1956).

15. HolmberG, A., Ultrastructural Changes in the Ciliary Epithelium Following Inhibition of Secretion of Aqueous Humor in the Rabbit Eyes. Karolinska Institutet, Stockholm, 1957.

16. Kemp, N. E., J. Biophys. Biochem. Cytol. 2, 281 (1956).

17. - Anat. Record 130, 324 (1958).

18. Kemp, N. E. and Allen, M. D., Biol. Bull. 111, 293 (1956).

19. Kessel, R. G., Exptl. Cell Research 22, 108 (1961).

20. KING, R. C. and Devine, R. L., Growth, 22, 299 (1958).

21. Knaben, N., Mull. Bergens Mus. Aarb. 1, 1 (1936).

22. Odor, L. D., Anat. Record 133, 453 (1959).

23. Palade, G. E., J. Appl. Phys. 24, 1424 (1953).

24. _- J. Biophys. Biochem. Cytol. 1, 567 (1955).

25. - Anat. Record 136, 254 (1960).

26. Paladino, G., Anat. Anz. 5, 254 (1890).

27. Palay, S. L. and Palade, G. E., J. Biophys. Biochem. Cytol. 1, 59 (1955).

28. Press, N., Exptl. Cell Research 18, 194 (1959).

29. Rebhun, L. I., J. Biophys. Biochem. Cytol. 2, 159 (1956).

30. Regaud, C. and Dubreuil, G., Verhandl. Anat. Ges. 152 (1908).

31. Retzius, G., Biol. Untersuch. 17, 45 (1912).

32. SAger, R. and Palade, G. E., J. Biophys. Biochem. Cytol. 3, 463 (1957).

33. Seeliger, O., Tunicata, in Bronn's Tier-Reichs. Suppl. Bd. 3, Abt., 1-1, pp. 1-1280 (1893-1907).

34. Sotelo, J. R. and Trujillo-Cenoz, O., J. Biophys. Biochem. Cytol. 3, 301 (1957).

35. — Asoc. Latinoam. Cienc. Fisiol. Reunion Cient. 163 (abstr) (1957).

36. Sotelo, J. R. and Porter, K. R., J. Biophys. Biochem. Cytol. 5, 327 (1959).

37. SPEK, J., Wilhelm Roux' Arch. Entwicklungsmech. Organ. 111, 119 (1927).

38. Trujtllo-Cénoz, O. and Sotelo, J. R., J. Biophys. Biochem. Cytol. 5, 347 (1959). 
39. TuCker, G. H., J. Morphol. 70, 81 (1942).

40. VAN Beneden, E. and Julin, C. Arch. Biol. 6, 237 (1887).

41. Wartenberg H. and Gusek, W., Exptl. Cell. Research 19, 199 (1960).

42. Watson, M. L., J. Biophys. Biochem. Cytol. 1, 257 (1955).

43. Wischnitzer, S., J. Biophys. Biochem. Cytol. 3, 1040 (1957).

44. YamadA, E., J. Biophys. Biochem. Cytol. 1, 455 (1955).

45. Yamada, E., Muta, T., Motomura, A. and Koga, H., Kurume Med. J. 4, 148 (1957).

46. Yasuzumi, G. and Tanaka, H., Exptl. Cell Research 12, 681 (1957).

47. ZetTerqvist, H., The Ultrastructural Organization of the Columnar Absorbing Cells of the Mouse Jejunum. Karolinska Institutet, Stockholm, Aktiebolaget Godvill, 1956. 